\title{
Prediction of Theophylline Clearance in Various Stages of Liver Cirrhosis by Child-Pugh and MELD Scores: A Population Pharmacokinetic Analysis
}

\author{
Yasuo Kurata $^{1}$, Shota Muraki ${ }^{2}$, Takeshi Hirota ${ }^{3}$, Hiroshi Araki ${ }^{1}$, and Ichiro Ieiri ${ }^{4}$ \\ ${ }^{1}$ Fukuoka City Hospital \\ ${ }^{2}$ Kyushu University \\ ${ }^{3}$ Kyushu University Hospital \\ ${ }^{4}$ Affiliation not available
}

July 28, 2021

\begin{abstract}
Aims Theophylline clearance in patients with chronic liver diseases (CLDs), chronic hepatitis (CH) and liver cirrhosis (LC), was evaluated by population pharmacokinetic (PPK) analysis. Methods PPK analysis included 433 minimum steady-state concentrations from 192 Japanese bronchial asthma patients and was performed using NONMEM. The severity of LC was assessed by the Child-Pugh (CP) class and model for end-stage liver disease (MELD) score. Results Two final models (CP and MELD models) were obtained, and described apparent theophylline clearance $(\mathrm{CL} / \mathrm{F})$ as follows: $\mathrm{CP}$ model: $\mathrm{CL} / \mathrm{F}=0.0473 \times 0.874 \mathrm{CH} \times 0.697 \mathrm{CPA} \times 0.592 \mathrm{CPB} \times 0.441$ MELD model: $\mathrm{CL} / \mathrm{F}=0.0472 \times 0.876 \mathrm{CH} \times 0.687 \mathrm{MELD}<10 \times 0.568 \mathrm{MELD} 10-14 \times 0.487 \mathrm{MELD} 15-19 \times 0.417 \mathrm{MELD} 20-24 \times 0.328 \mathrm{MELD}$ [?] 25. The CP model showed that mean CL/F in patients without CLDs, and with CH, and LC with CP class A, B, and C was 0.0473, 0.0413, 0.0330, 0.0280, and $0.0209 \mathrm{~L} / \mathrm{h} \mathrm{kg-1}$, respectively. The MELD model predicted that CL/F in patients without CLDs, and with CH, and LC with a MELD score of < 10, 10-14, 15-19, 20-24, and [?] 25 was 0.0472, 0.0413, 0.0324, 0.0268, $0.0230,0.0197$, and $0.0155 \mathrm{~L} / \mathrm{h} \mathrm{kg-1}$, respectively. Conclusions CL/F in various stages of LC was evaluated and a change in $\mathrm{CL} / \mathrm{F}$ was highly dependent on the severity of CLDs in both models. The MELD model classified LC into 5 categories, and subdivided CP class C patients into 3 further categories. The MELD model provided a more accurate and precise description of $\mathrm{CL} / \mathrm{F}$ than the $\mathrm{CP}$ model, particularly in high-severity LC patients.
\end{abstract}

\section{Hosted file}

Manuscript.docx available at https://authorea.com/users/428051/articles/532060-predictionof-theophylline-clearance-in-various-stages-of-liver-cirrhosis-by-child-pugh-and-meldscores-a-population-pharmacokinetic-analysis

\section{Hosted file}

Figures.pptx available at https://authorea.com/users/428051/articles/532060-predictionof-theophylline-clearance-in-various-stages-of-liver-cirrhosis-by-child-pugh-and-meldscores-a-population-pharmacokinetic-analysis

\section{Hosted file}

Tables.docx available at https://authorea.com/users/428051/articles/532060-prediction-oftheophylline-clearance-in-various-stages-of-liver-cirrhosis-by-child-pugh-and-meldscores-a-population-pharmacokinetic-analysis 